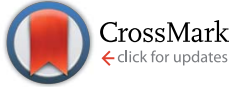

Cite this: RSC Adv., 2017, 7, 7820

Received 6th December 2016 Accepted 18th January 2017

DOI: 10.1039/c6ra27824h

www.rsc.org/advances

\title{
Bio-oil production via catalytic solvolysis of biomass
}

\author{
Duo Yao Rachel-Tang, ${ }^{\text {ab }}$ Aminul Islam ${ }^{\text {*acd }}$ and Yun Hin Taufiq-Yap ${ }^{\star a b}$
}

Recent studies have found that biomass has great potential as a substitute for natural fossil fuels. Although pyrolysis has always been the option for biomass-to-biofuel conversion, liquefaction technology on the other hand appears to be another alternative to obtain valuable high energy products such as biofuel, gas and char due to some disadvantages of converting biomass to biofuel via pyrolysis. In this study, the optimization of liquefaction of oil palm empty fruit bunch (EFB) into bio-oil was studied over a series of supported Zn catalysts. 15 wt\% of Zn supported on ZSM-5 showed the highest bio-oil yield conversion after the introduction of catalyst. GC-MS analysis of the bio-oil showed it to mainly consist of furfurals, followed by phenols and other minor compounds. Several parameters that were studied include the effect of reaction temperature, reaction time, catalyst composition, and catalyst loading on the product yield. The optimum conditions for the conversion of EFB (43.6\%) to liquid products were $180{ }^{\circ} \mathrm{C}$ for 90 min with $0.5 \mathrm{wt} \%$ of $15 \%$ Zn supported on ZSM-5.

\section{Introduction}

Global energy consumption which rises exponentially with rapid population increments and industrial development is facing a critical situation with the gradual depletion of limited natural fossil fuel reserves. This phenomenon raises the urgency for the substitution of energy from natural fossil fuel with other alternatives. Renewable energy appears to be a promising and potential source to replace the existing energy source. Energy sources that could be renewed include solar, wind, hydro, biomass, nuclear, etc. ${ }^{1}$ Among these renewables, the abundancy of biomass all around the world has increased its utilization in many aspects and so, is replacing crude-based non-renewable energy resources.

In general, biomass which includes agricultural crops, forestry residues, municipal and solid waste etc. could be converted and used in various applications such as transportation fuels, value-added chemicals, fertilizers and agro-chemicals. ${ }^{2,3}$ Biomass could be converted biologically (fermentation and anaerobic digestion) or thermochemically (pyrolysis, gasification and liquefaction). ${ }^{4}$ Among these two routes of methods, thermochemically-converted biomass is considered to be more

${ }^{a}$ Catalysis and Science Research Center, Faculty of Science, University Putra Malaysia, UPM, Serdang,43400,Selangor, Malaysia.E-mail: md.aminul@ums.edu; taufiq@ upm.edu.my; Fax: +60-3-89466758; Tel: +60-3-89466809

${ }^{b}$ Department of Chemistry, Faculty of Science, University Putra Malaysia, UPM, Serdang, 4340o, Selangor, Malaysia

${ }^{c}$ Faculty of Engineering, Universiti Malaysia Sabah, 88400 Kota Kinabalu, Sabah, Malaysia

${ }^{d}$ Energy Research Unit, University Malaysia Sabah, 88400 Kota Kinabalu, Sabah, Malaysia promising in obtaining product in three phases: low molecular weight liquid, gas fuel and solid residue. ${ }^{5}$

In the past two decades, pyrolysis has always been selected for the bio-oil production. However, although pyrolysis technology is a promising way to give high yield product, it has become less favorable as reaction time needed is long and temperature needed for this method is high. High operating temperature of pyrolysis (673-1273 K) give forth to a very big problem: cross-linking and re-combination reaction between hydrocarbons and aromatics. This may further lead to tar and char formation which eventually causes difficulty in decomposition. ${ }^{6}$ In addition, pyrolysis requires dry biomass in basis prior every treatment and this will lead to substantial energy consumption due to high heat of water vaporization. ${ }^{7}$ It is therefore unfeasible from the view of economy.

In contrast to pyrolysis, solvolytic liquefaction is more preferable as biomass could be converted into valuable materials under relatively low temperature and shorter reaction time. Not only that, the presence of solvent during solvolysis liquefaction will help to avoid cross-linked reactions and reverse reactions by diluting the product concentration. ${ }^{8-10}$ Drying of biomass prior liquefaction treatment is not needed as liquefaction can also convert biomass with high moisture content. The thermochemically converted liquid product produced from biomass is called bio-oil. Chemicals extracted from bio-oil are used as food flavorings, resins, adhesives, agrichemicals, and fertilizers. In addition, bio-oil is also used for power generation for diesel engines and turbines.

Malaysia is one of the major producers of palm oil in the world. Hence, the abundance availability of oil palm empty fruit bunch (EFB) has become a great option to be used as the feedstock of biomass-to-biofuel conversion. It was reported that 
as in 2010, Malaysia contributed incredible amount of oil palm biomass waste, approximately 86.9 Mt per year ${ }^{.11,12}$ As such, the abundance of oil palm biomass waste can be served as feedstock for biomass to biofuel conversion. ${ }^{\mathbf{1 3 , 1 4}}$

Several articles on the liquefaction off biomass have been reported. Fan et al. ${ }^{15}$ investigated the effect of different solvents on the oil palm empty fruit bunch via solvolysis liquefaction. Similarly to Fan et al.,${ }^{15}$ Yip et al. ${ }^{16}$ carried out the investigation of the effect of various solvents on the liquefaction of bamboo. On the other hand, the liquefaction of pinewood dust by using various solvents (carbon dioxide, water, ethanol and acetone) with the presence of catalysts (alkali salts and acidic zeolites) was studied by Wang et al. ${ }^{17}$ Catalytic hydrothermal liquefaction of wood biomass has also been done by Karagöz et al. ${ }^{18}$ in the presence of alkaline solution. Yan et al. ${ }^{19}$ also investigated the effect of various parameters which includes temperature, reaction time and solvent type on the liquefaction of sawdust. The productions of bio oil from rice husk, coconut shell, straw, corn stalk were reported in the literature..$^{20-23}$ Several recent studies have concentrated on the identification of protein molecular structure, energy values and biodegradation properties of biooil. ${ }^{24,25}$ An alternative approach to produce bio oil based on the ultrasonic pretreatment technology as an alternative to conventional process has been highlighted recently. ${ }^{26}$

Although several studies and investigations have been performed on the bio-oil production of biomass via solvolysis liquefaction, there are little studies on the effect of heterogeneous catalysts that affect the yield and chemical composition of the liquid product via solvolysis liquefaction. The main purpose of this study is to find a suitable heterogeneous catalyst that can convert biomass (palm oil empty fruit bunch) into biooil via solvolysis liquefaction under optimum conditions. Zeolite (ZSM-5) was chosen in this study as a support material due to their large surface area, excellent reactivity and stability, unique pore structure and shape selectivity and $\mathrm{ZnO}$ was loaded on ZSM-5 to adjust the acid properties and introduce active species to make effective catalysts for bio-oil synthesis.

\section{Result and discussion}

\section{Structure of catalyst}

In this study, heterogeneous catalyst was employed to enhance the production of the bio-oil and the surface science of the catalyst was studied. Firstly, the crystallinity of the catalyst was determined by X-ray diffraction method and the XRD pattern of the synthesized catalysts is given in Fig. 1. The XRD pattern of the parent catalyst - commercial zeolite ZSM-5 that has been calcined (labelled as ZC) was compared to the synthesized catalyst (i.e. zinc with different weight percentage wt\% supported on ZC). After calcination at $550{ }^{\circ} \mathrm{C}$ as an activation step of the ZSM-5, the five diffraction characteristic peaks the Mordenite Framework Inverted (MFI) structure of ZSM-5 could be observed. The first two peaks were observed at $2 \theta=7-10^{\circ}$ and the other three peaks were observed at $2 \theta=22-25^{\circ}$. This phenomenon is in agreement of what has been reported by Ren et $a .^{12}$ and Zhao et $a .^{13}$ As for the other four synthesized catalysts, the five diffraction characteristic peaks were also observed

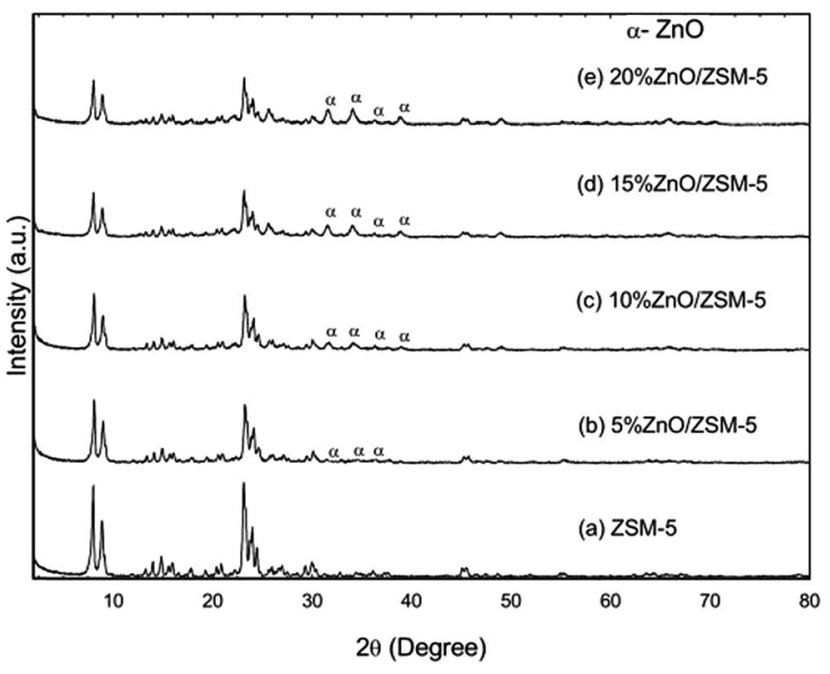

Fig. 1 X-ray diffraction pattern of the parent catalyst (a) ZSM-5 and the synthesized catalysts of different zinc composition: (b) 5\% ZnO/ZSM5; (c) $10 \% \mathrm{ZnO} / \mathrm{ZSM}-5$; (d) $15 \% \mathrm{ZnO} / \mathrm{ZSM}-5$; (e) $20 \% \mathrm{ZnO} / \mathrm{ZSM}-5$. The peaks for $\mathrm{ZnO}$ for all modified catalysts are defined as $\alpha$.

at the same position, indicating the addition of zinc did not affect the basic structure of the parent ZSM-5. In addition, it is clearly shown that as the amount of zinc loaded onto ZC increased up to $20 \mathrm{wt} \%$, the intensity of the peaks of zinc at the same degree also increased, indicating a higher amount of zinc dispersed on the parent catalyst. However some low intensity peaks were observed and this was caused by the limitation of the instrument. ${ }^{14}$

\section{Acidity of catalyst}

The acidity of the catalyst were studied by using temperature programmed desorption with $\mathrm{NH}_{3}$ as probe molecule (TPD- $\mathrm{NH}_{3}$ ).

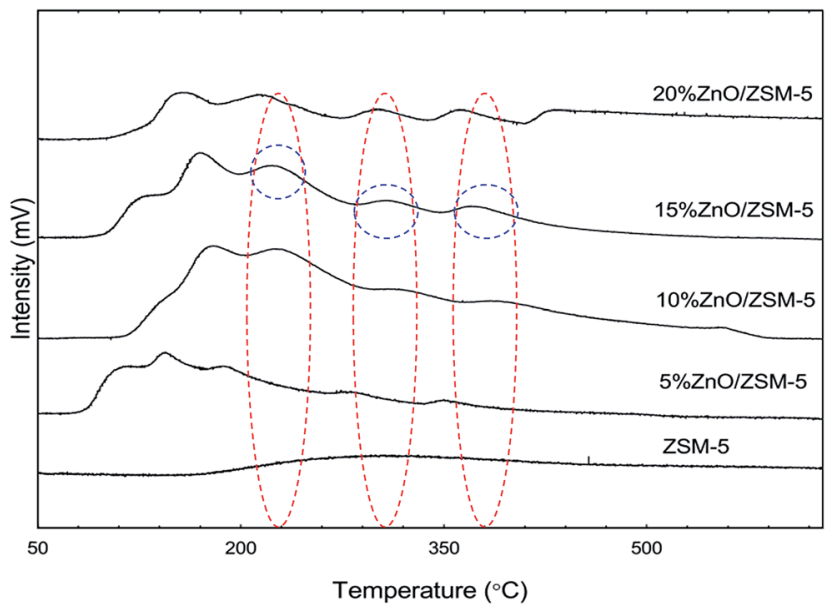

Fig. 2 TPD $-\mathrm{NH}_{3}$ of $\mathrm{ZSM}-5$ (ZC), 5\% ZnO/ZSM-5, 10\% ZnO/ZSM-5, 15\% $\mathrm{ZnO} / \mathrm{ZSM}-5$ and $20 \% \mathrm{ZnO} / \mathrm{ZSM}-5$. Red colored circles depicts the desorbed temperature at weak, medium and strong acid sites; blue colored circles depicts the desorbed temperature for weak, medium and strong acid sites for the best performing catalyst in bio-oil production. 
Table 1 The composition analysis of EFB fibre

\begin{tabular}{ll}
\hline Properties & Values \\
\hline Moisture (\%) & 8.99 \\
Proximate analysis (\%) & \\
Dry matter & 91.01 \\
Ash & 2.42 \\
& \\
Chemical composition (\%) & \\
Hemicellulose & 41.32 \\
Cellulose & 39.07 \\
Lignin & 34.82 \\
& \\
Ultimate analysis (\%) & \\
C & 45.44 \\
H & 6.22 \\
N & 1.58 \\
S & 0.36 \\
O & 46.40 \\
\end{tabular}

Table 2 The acidity of the catalysts

\begin{tabular}{ll}
\hline Catalysts & $\mathrm{NH}_{3}$ desorbed $\left(\mu \mathrm{mol} \mathrm{g}^{-1}\right)$ \\
\hline ZSM-5 & 6619.32 \\
$5 \% \mathrm{ZnO} / \mathrm{ZSM}-5$ & 2829.63 \\
$10 \% \mathrm{ZnO} / \mathrm{ZSM}-5$ & 17373.85 \\
$15 \% \mathrm{ZnO} / \mathrm{ZSM}-5$ & 17847.18 \\
$20 \% \mathrm{ZnO} / \mathrm{ZSM}-5$ & 14186.61
\end{tabular}

Fig. 2 shows the board asymmetric desorption profile of the five catalysts used in this study. On the other hand, the amount of $\mathrm{NH}_{3}$ desorbed is shown in Table 2. The peaks observed represent desorption of the $\mathrm{NH}_{3}$ molecules. Peaks could be observed at the range of $100-200,200-350$ and above $350{ }^{\circ} \mathrm{C}$ respectively. $\mathrm{NH}_{3}$ molecules desorbing at temperature $100-200{ }^{\circ} \mathrm{C}$ indicates the weak acid sites of the catalysts, while those desorbing at the range of $200-350^{\circ} \mathrm{C}$ indicates medium acid sites and those above $350^{\circ} \mathrm{C}$ indicates acidity with strong acid strength. As compared to the parent ZSM-5, the number of acid sites for all the doped catalysts increases as zinc was loaded and that correspond to the amount of gas that was desorbed with the increase of zinc concentration from 5 to $15 \mathrm{wt} \%$. As the zinc composition increases, weak acid sites and medium acid sites increases, while strong acid sites only present when the composition reaches 15 wt $\%$ onwards. The increase in strong acid site with the introduction of zinc species could be ascribed to the increased exchange rate between $\mathrm{Zn}^{2+}$ and $\mathrm{H}^{+}$as a result of the large amount of zinc species deposited on the catalyst surfaces.

\section{Composition of catalyst}

The composition of the synthesized catalysts was identified by using EDX analysis. From the spectrum of the chosen area of the catalyst ( $15 \mathrm{wt} \% \mathrm{Zn} / \mathrm{ZnO}$ ), the weight percentage of oxygen, aluminium, silica and zinc are $62.04 \%, 1.67 \%, 30.87 \%$ and $5.42 \%$ respectively. Fig. 3a1-a4 clearly showed the distribution of the zinc being introduced, stirred and refluxed. The distribution of the zinc was good, even and well dispersed as shown by the purple-colored dots under EDX analysis. On the other hand, the spectrum of the catalyst can be seen in Fig. 3b. The composition of the parent ZSM- 5 and other catalysts are displayed in Table 3. For ZSM-5, there is zero amount of zinc components detected as there ZSM- 5 is purely only zeolite ZSM5. When zinc was added, the EDX analysis was able to detect the presence of zinc, giving the zinc wt $\%$ as shown in table. However, the detected amount may not be accurate, but the presence of zinc in the modified catalysts was proofed. The amount for zinc on $20 \% \mathrm{Zn} / \mathrm{ZSM}-5$ was found to be specifically high, most probably due to agglomeration of zinc. This occurrence was very in line with all other characterization that was done on the same amount of zinc introduced. Nevertheless, the synthesis of zinc on zeolite ZSM-5 was acceptable and the zinc that was introduced was well-deposited on the surface of the parent catalyst.

\section{Surface area of catalyst}

Table 4 summarizes the specific surface area of each synthesized catalyst. From the result, the specific surface area of calcined zeolite was found to be $332.15 \mathrm{~m}^{2} \mathrm{~g}^{-1}$. As the composition of the zinc being loaded increased, the specific surface area of the synthesized catalyst showed declination, $211.72 \mathrm{~m}^{2}$ $\mathrm{g}^{-1}, 209.44 \mathrm{~m}^{2} \mathrm{~g}^{-1}$ and $138.57 \mathrm{~m}^{2} \mathrm{~g}^{-1}$ for $5 \% \mathrm{ZnO} / \mathrm{ZSM}-5,10 \%$ ZnO/ZSM-5 and $15 \% \mathrm{ZnO} / \mathrm{ZSM}-5$ respectively. One of the possible reasons for this phenomenon is the loading of zing has already been deposited on the surface of the parent catalyst which caused a decrease in the surface area obtained as zinc concentration increased. However, when the amount of zinc further increased to $20 \mathrm{wt} \%$, a slight increase in the specific surface area was observed. The surface area was found to be $164.29 \mathrm{~m}^{2} \mathrm{~g}^{-1}$. According to the noticeable trend from $5 \mathrm{wt} \%$ to $15 \mathrm{wt} \%$ synthesized catalysts, the surface area of $20 \mathrm{wt} \%$ synthesized catalyst should show declination instead of increment. The possible reason for this phenomenon was due to agglomeration of the zinc that has been loaded. Zinc that has been introduced may not be evenly dispersed; some of the zinc might adhere tightly to one another, resulting the agglomeration of the dopant on the surface of the parent catalyst. Similar observation was also reported by Zhao et al. ${ }^{13}$ Other possible reason might be due to other side reaction that happens between the parent catalyst and the dopant, and so the surface area for $20 \mathrm{wt} \% \mathrm{ZnO} / \mathrm{ZSM}-5$ showed some slight increase.

\section{Morphologies of catalyst}

Fig. 4 shows the surface morphologies of the five catalysts. The surface morphologies were analyzed using a field emission scanning electron microscope (FEI Quanta SEM Model 400F) equipped with an energy dispersive X-ray (EDX) feature. From the figures, all catalysts show irregular shapes throughout the surface of the catalysts. As zinc was introduced into the parent ZSM-5 which can been seen from figure (b) onwards, small cloud-like shaped particles were observed, and this indicates the addition of the zinc onto the parent ZSM-5. This is however 

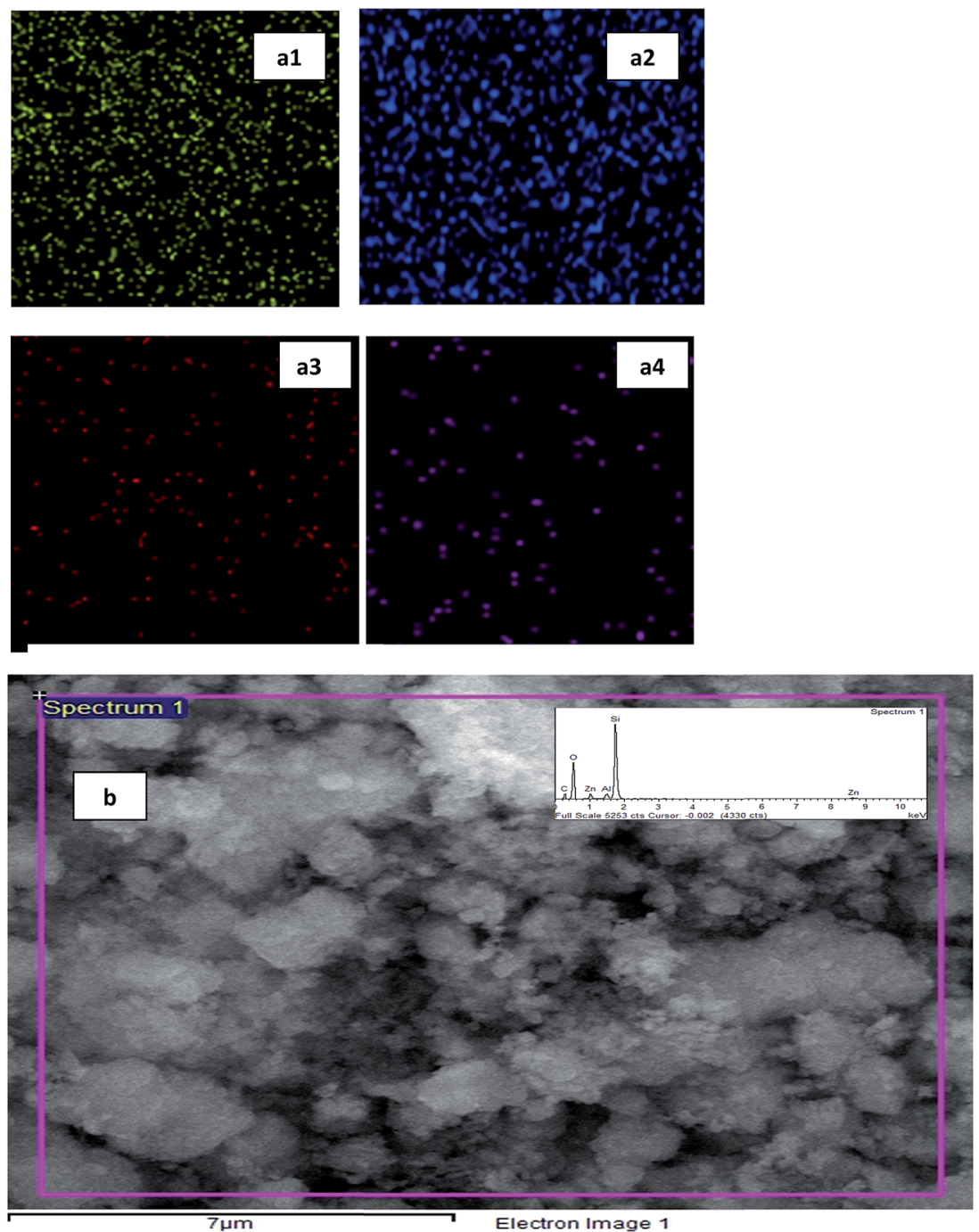

Fig. 3 Composition distribution of 15 wt\% Zn/ZSM-5 catalyst: (a1) oxygen, (a2) alumina, (a3) silica and (a4) zinc. (b) The spectrum of the synthesized catalyst at $20000 \times$ magnification.

Table 3 Weight percentage (\%) of each element for each modified catalysts

\begin{tabular}{lllll}
\hline & \multicolumn{4}{l}{ EDX elemental analysis (wt\%) } \\
\cline { 2 - 5 } Catalyst & $\mathrm{Al}$ & $\mathrm{Si}$ & $\mathrm{O}$ & $\mathrm{Zn}$ \\
\hline ZSM-5 & 1.89 & 31.47 & 66.64 & - \\
$5 \%$ Zn/ZSM-5 & 1.90 & 36.87 & 55.76 & 5.47 \\
$10 \%$ Zn/ZSM-5 & 1.69 & 35.95 & 56.05 & 6.36 \\
$15 \%$ Zn/ZSM-5 & 1.67 & 30.87 & 62.04 & 5.42 \\
$20 \%$ Zn/ZSM-5 & 1.51 & 16.85 & 48.07 & 33.57
\end{tabular}

not observed in (e) when the zinc concentration reached 20 wt $\%$. The morphology of $20 \% \mathrm{ZnO} / \mathrm{ZSM}-5$ was totally different and cloud-like shaped particles was not observed in this particular figure. Agglomeration might have occurred elsewhere and this is consistent with the result of BET and TPD-NH $\mathrm{N}_{3}$ which showed declination in both characterizations.
Table 4 Specific surface area of each catalyst

\begin{tabular}{ll}
\hline Catalyst & $\begin{array}{l}\text { Specific surface } \\
\text { area }\left(\mathrm{m}^{2} \mathrm{~g}^{-1}\right)\end{array}$ \\
\hline ZSM-5 & 332.15 \\
$5 \% \mathrm{ZnO} / \mathrm{ZSM}-5$ & 211.72 \\
$10 \% \mathrm{ZnO} / \mathrm{ZSM}-5$ & 209.44 \\
$15 \% \mathrm{ZnO} / \mathrm{ZSM}-5$ & 138.57 \\
$20 \% \mathrm{ZnO} / \mathrm{ZSM}-5$ & 164.29 \\
\hline
\end{tabular}

\section{Analysis of the composition of bio-oil by GC-MS}

The bio-oil obtained has been analyzed by using gas chromatography mass spectrometry (GC-MS). This is to find out the composition of the compounds in the bio-oil that has been produced. Although the yield of bio-oil produced was quite low, the aim of this study is to determine the composition of the bio-oil produced with and without the presence 

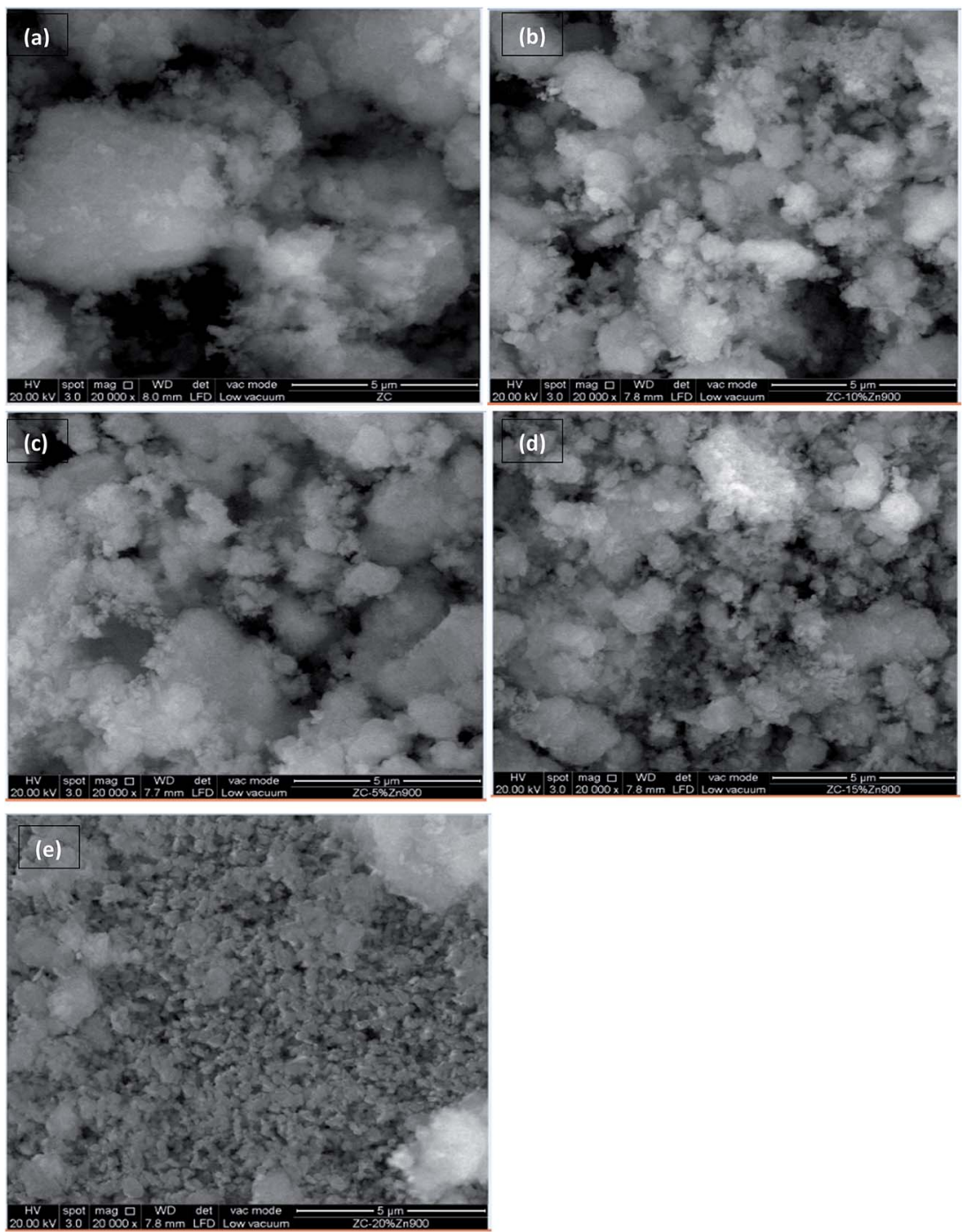

Fig. 4 FESEM of (a) ZC, (b) 5\% ZnO/ZSM-5, (c) 10\% ZnO/ZSM-5, (d) 15\% ZnO/ZSM-5 and (e) 20\% ZnO/ZSM-5 at $20000 \times$ magnification.

of catalyst. The compositions of bio-oil vary considerably due to the many variables in the pyrolysis of biomass. The wide range of compounds is reported for the composition of each organic component of bio-oil. The literature on the composition of bio oils was summarized by Milne et $a .^{27}$ The results of this study was correlated with the compositions of bio oil

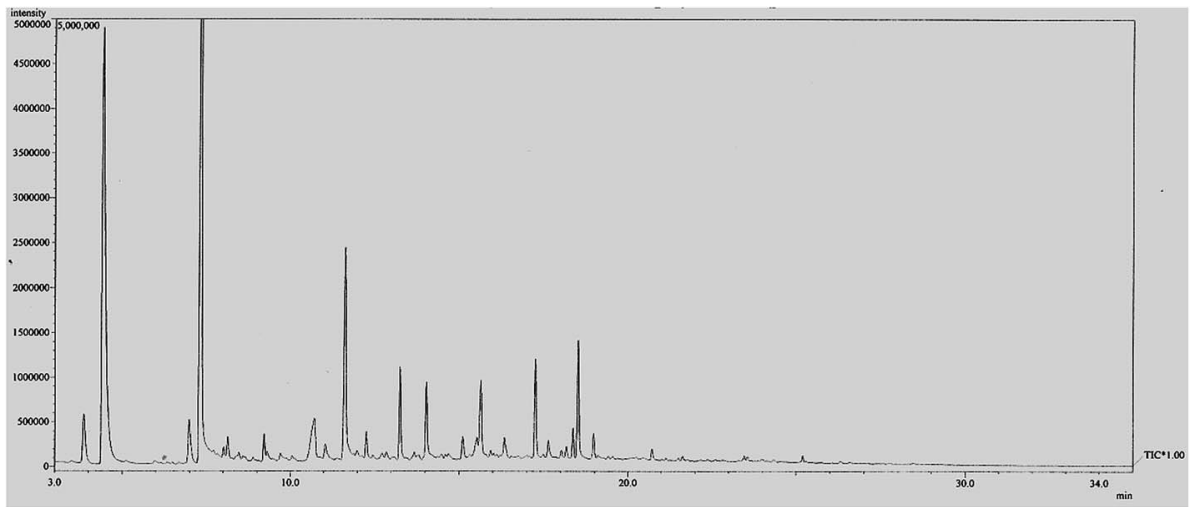

Fig. 5 GC-MS graph of bio-oil obtained without the presence of catalyst at optimum condition. Reaction conditions: EFB amount of 5.0 g, reaction time of $90 \mathrm{~min}$, reaction temperature of $180^{\circ} \mathrm{C}$. 
reported in the literature. ${ }^{27}$ The GC-MS graph of bio-oil in the absence of catalyst could be seen in Fig. 5. The reaction was set to be performed at $180^{\circ} \mathrm{C}$ for $90 \mathrm{~min}$ with a fixed amount of EFB fiber of $5.0 \mathrm{~g}$. From the figure, it could be seen that without the presence of any catalyst, there were many peaks that could be observed. All the observed peaks indicate the likelihood of certain compounds contained in the bio-oil after solvolysis process. The percentage of similarity of a particular compound found is directly proportional to the area under graph of the spectrum. Table 5 further explains the list of compounds in the bio-oil produced under this reaction condition. Many compounds were being found, such as furfural, phenol, and other minor compounds like benzoic acid etc. Although phenolic compounds hold the highest percentage of the overall compounds found, the selectivity of the compounds produced was not high. The production of value-added chemicals such as furfural and phenols were not enhanced without the introduction of catalyst. However, when catalyst was introduced under the same reaction condition, especially after the incorporation of zinc oxide onto ZSM-5 catalyst, the selectivity of the compounds in biooil produced found to improve greatly as when the amount of zinc was increased from $5 \mathrm{wt} \%$ to $20 \mathrm{wt} \%$ with $5 \mathrm{wt} \%$ interval. Under optimum condition ( $15 \mathrm{wt} \%$ of zinc incorporated on ZSM-5), 83\% furfural was detected in the bio-oil which is a very valuable chemical for many industrial applications. The list of relatively high content compounds obtained from the bio-oil with the presence of catalyst under optimum condition is shown in Table 5 and the GC-MS graph of bio-oil with the presence of catalyst is shown in Fig. 6. As compared to the bio-oil obtained without the presence of catalyst, the selectivity of compounds of the former bio-oil was not high. Most of the compounds have not been totally break down into desirable compounds. In contrast, with the help of catalyst, the selectivity of compounds increased and the products produced are more narrowed and controllable (Table 6).

In non-catalytic bio-oil, more aromatic hydrocarbons and its derivatives were produced with phenol as the most abundant compound. Also, a certain content of oxygenates such as ketones was found too. In this present work, the incorporation of $\mathrm{ZnO}$ into zeolite supports decreases the overall production of aromatic hydrocarbons. This phenomenon suggests that the incorporation of the metal oxide into zeolite support modifies the acid features of the support and thus enhance the selectivity of the compound produced in the bio-oil.

Table 5 Compound found in bio-oil converted without the presence of catalyst under $180^{\circ} \mathrm{C}$ for 90 min

\begin{tabular}{|c|c|c|c|}
\hline No. & Compound & Area $(\%)$ & SI index \\
\hline 1 & Furfural & 25.06 & 98 \\
\hline 2 & Phenol & 28.04 & 99 \\
\hline 4 & 5-Methyl-2-furancarboxaldehyde & 1.87 & 97 \\
\hline 5 & 2,3-Dihydroxybenzaldehyde & 1.43 & 82 \\
\hline 6 & Benzoic acid & 2.92 & 98 \\
\hline 9 & Vanillin & 2.20 & 96 \\
\hline 10 & 1-(4-Isopropoxy-3-methoxyphenyl)-propan-2-one & 1.40 & 88 \\
\hline 11 & $7 a$-Methyl-2,3,7,7a-tetrahydro- $1 H$-indene-1,5(6H)-dione & 1.25 & 83 \\
\hline 12 & 4-Hydroxy-3,5-dimethoxy-benzaldehyde & 2.67 & 92 \\
\hline 13 & 6,7-Dimethyl-1 $H$-pyrrolo[3,4-c]pyridine-1,3,4 $(2 H, 5 H)$-trione & 3.39 & 71 \\
\hline
\end{tabular}

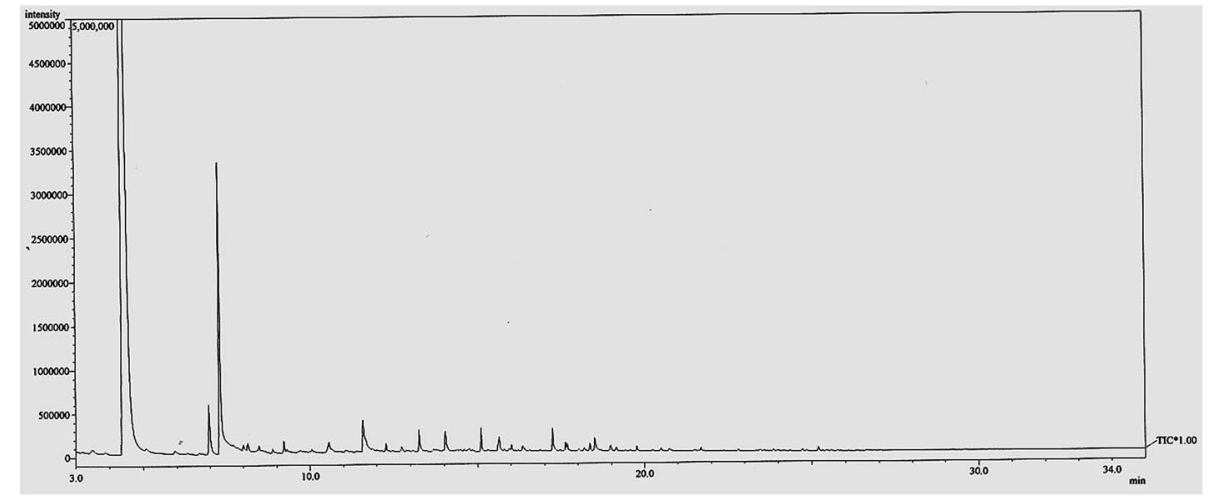

Fig. 6 GC-MS graph of bio-oil obtained with the presence of catalyst under optimum condition. Reaction conditions: EFB amount of $5.0 \mathrm{~g}$, reaction time of $90 \mathrm{~min}$, reaction temperature of $180{ }^{\circ} \mathrm{C}$, catalyst loading of $0.5 \mathrm{w} / \mathrm{w} \%$, ZnO amount of $15 \mathrm{wt} \%$ of ZSM-5. 
Table 6 Composition of bio-oil obtained under optimum condition

\begin{tabular}{llrl}
\hline No. & Compound & Area (\%) & SI index \\
\hline 1 & Furfural & 82.42 & 98 \\
2 & Phenol & 8.18 & 98 \\
3 & 5-Methyl-furfural & 1.53 & 97 \\
4 & 2-Furancarboxaldehyde & 0.92 & 92 \\
5 & 2,6-Dimethoxy-phenol & 0.48 & 97 \\
6 & 4-Hydroxy-3-methoxy-benzaldehyde & 0.48 & 97 \\
7 & 2,6-Bis(1,10-dimethylethyl)-4-methyl-phenol & 0.42 & 91 \\
8 & 4-Hydroxy-3,5-dimethoxy-benzaldehyde & 0.46 & 92 \\
& & & \\
\hline
\end{tabular}

\section{Effect of temperature on yield}

The conversion of EFB relative to temperature can be seen in Fig. 7. A range of temperature has been selected to study the effect of temperature on the conversion of EFB fibers into biooil with the presence of catalyst. The EFB fibers were subjected to temperature ranging from $160{ }^{\circ} \mathrm{C}$ up to $220{ }^{\circ} \mathrm{C}$ with the presence of the optimum composition of catalyst, i.e. $15 \mathrm{wt} \%$ of zinc on ZSM-5. It was clearly stated that the optimum conversion of EFB was achieved at $180{ }^{\circ} \mathrm{C}$ with the optimum catalyst composition of $15 \mathrm{wt} \%$ of zinc in ZSM-5 for 90 minutes. The declination in the yield of bio-oil with further increase in temperature from the optimum temperature is also common in several works that have been reported. ${ }^{28-31}$ At higher temperatures, occurrence of competing reaction such as repolymerization, cyclization and condensation may convert bio-oil components that have been formed at the primary stage of liquefaction process to solid product char, water-soluble and gaseous products that are not able to be extracted as bio-oil. ${ }^{32,33}$

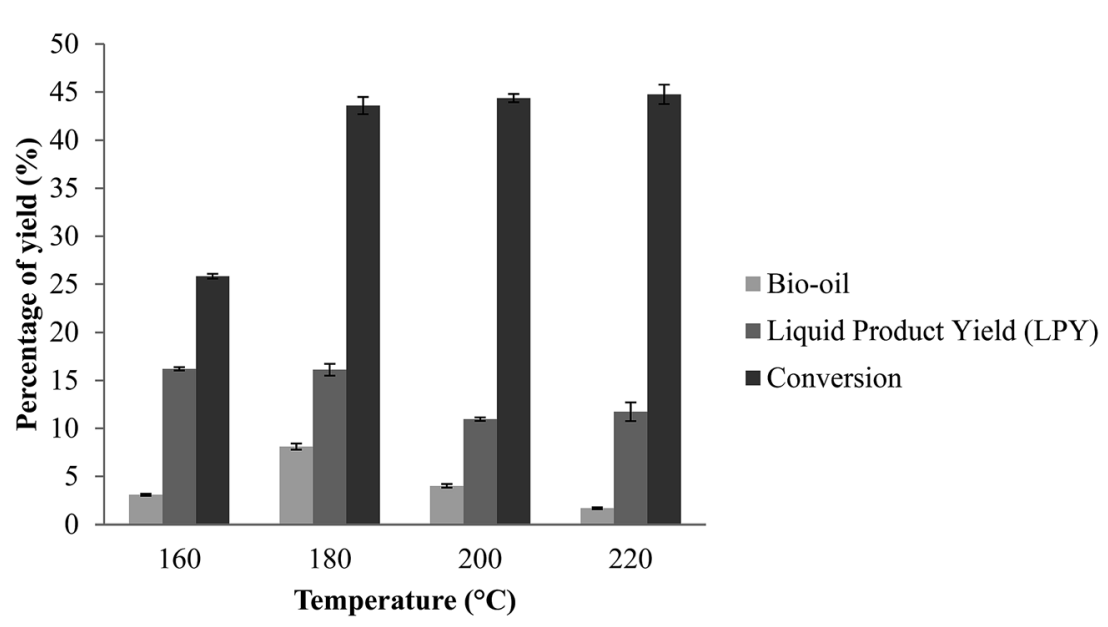

Fig. 7 Effect of temperature on yield. Reaction condition: EFB amount of 5.0 g, reaction time of 90 min, catalyst amount of 0.5 w/w\%, ZnO amount of $15 \mathrm{wt} \%$ of ZSM-5.

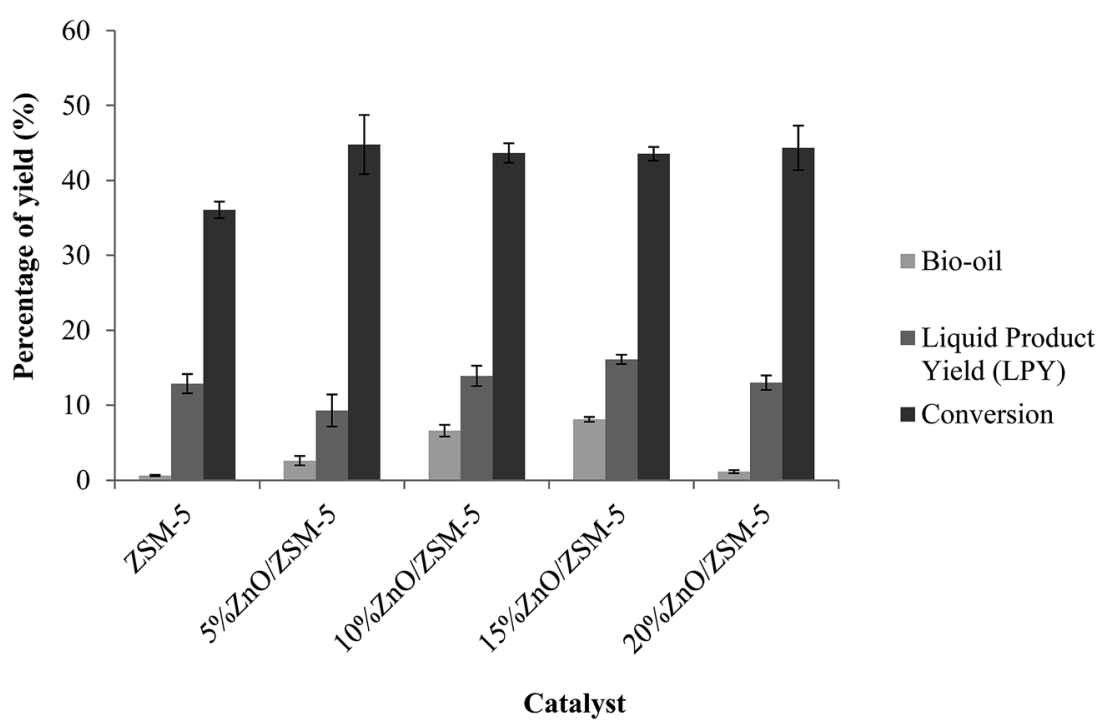

Fig. 8 Effect of zinc oxide concentration on yield. Reaction condition: EFB amount of 5.0 g, reaction temperature of $180{ }^{\circ} \mathrm{C}$, catalyst amount of $0.5 \mathrm{w} / \mathrm{w} \%$, reaction time of $90 \mathrm{~min}$. 


\section{Effect of catalyst composition on yield}

The effect of different catalyst composition on the conversion of EFB fibers to bio-oil is more clearly shown in Fig. 8. A series of test on different catalyst composition has been carried out on the conversion of EFB fibers to bio-oil. ZSM-5 was wet-impregnated with different zinc concentration, starting from $5 \mathrm{wt} \%$ and further increased at the interval of $5 \mathrm{wt} \%$ to a maximum of 20 $\mathrm{wt} \%$ of zinc in ZSM-5. With the absence of zinc in ZSM-5, percentage of bio-oil produced has slight increment compared to the conversion of EFB without any presence of catalyst. However when zinc was introduced into ZSM-5, conversion of bio-oil showed improvement and as the catalyst composition increased up to $15 \mathrm{wt} \%$, the percentage of bio-oil obtained was $8.10 \%$. However, the bio-oil obtained was decreased to $1.16 \%$ with $20 \mathrm{wt} \%$ zinc in ZSM-5 although the total conversion of the biomass increased to approximately $44 \%$.

As the content of zinc increases, the formation of furfural and furan derivatives increases. This could be due to highly dispersed species $\mathrm{Zn}$ ions that catalyzed the reaction. The increment in $\mathrm{Zn}$ content is equivalent to the increase in the active Lewis acid sites. It was found by $\mathrm{Lu}$ et $a .^{28}$ that acidic catalyst such as $\mathrm{ZnCl}_{2}$ could convert lignocelluloses biomass such as EFB into furfural. The declination of the bio-oil conversion when $20 \mathrm{wt} \%$ of $\mathrm{Zn}$ was introduced may be due to the agglomeration of $\mathrm{Zn}$, which is in agreement with the BET analysis that has been performed where the specific surface area of the $20 \mathrm{wt} \% \mathrm{Zn} / \mathrm{ZSM}-5$ is much lower than $15 \mathrm{wt} \% \mathrm{Zn} /$ ZSM-5.

It was reported that the isomerized compounds are mainly derived from biomass during the aqueous phase reaction. ${ }^{34}$ The major compound of bio oil obtained in this study is furfural can be enhanced through Brønsted and Lewis acid sites on $\mathrm{ZnO}$ supported ZSM-5 catalyst. Metal oxide catalysts in the zeolite could behave through the participation of the Lewis sites, although the actual mechanism is still debatable. A conclusion has been reached by several researchers ${ }^{35,36}$ that water shifts the reaction to proceed by intramolecular hydride shift, involving Lewis acid participation of oxide catalyst. Under this reactions, the xylose could be isomerized into xylulose, as reported by Choudhary et $a l^{37}$ Further, the dehydration of generated isomers over zeolite (ZSM-5), as proposed by Nakajima et al. ${ }^{35}$ can be proceed consistently with Brønsted acid sites to convert furfural, consistent with Scheme 1 . Consistent of this mechanism was also recently reported by Choudhary et al. ${ }^{36}$ employing Brønsted acid modified $\mathrm{CrCl}_{3}$ catalyst. In a related development, similar mechanism was proposed by Román-Leshkov, et $a l .{ }^{38}$ for glucose isomerization to fructose over $\mathrm{Sn}$ modified beta zeolite catalyst. Studies by Lew et $a l .{ }^{39}$ consistent with the glucose and xylose isomerization into fructose over Sn modified beta and MFI zeolites.
Xylose isomerization on Lewis acid site of catalyst

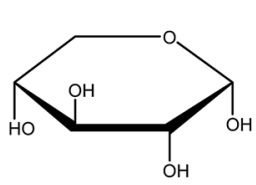

Xylose
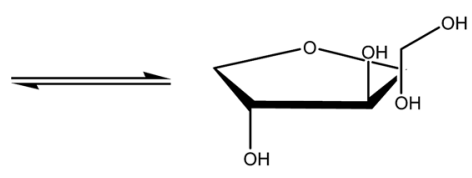

Xylulose
Xylulose dehydration

on Bronsted acid site of catalyst

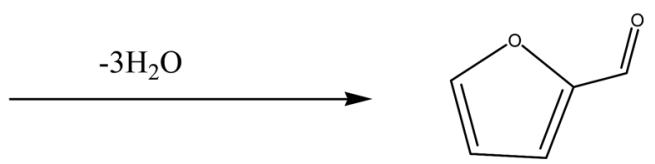

Furfural

Scheme 1 Proposed mechanism for biomass derived furfural formation over $\mathrm{ZnO}$ supported zeolite catalyst.

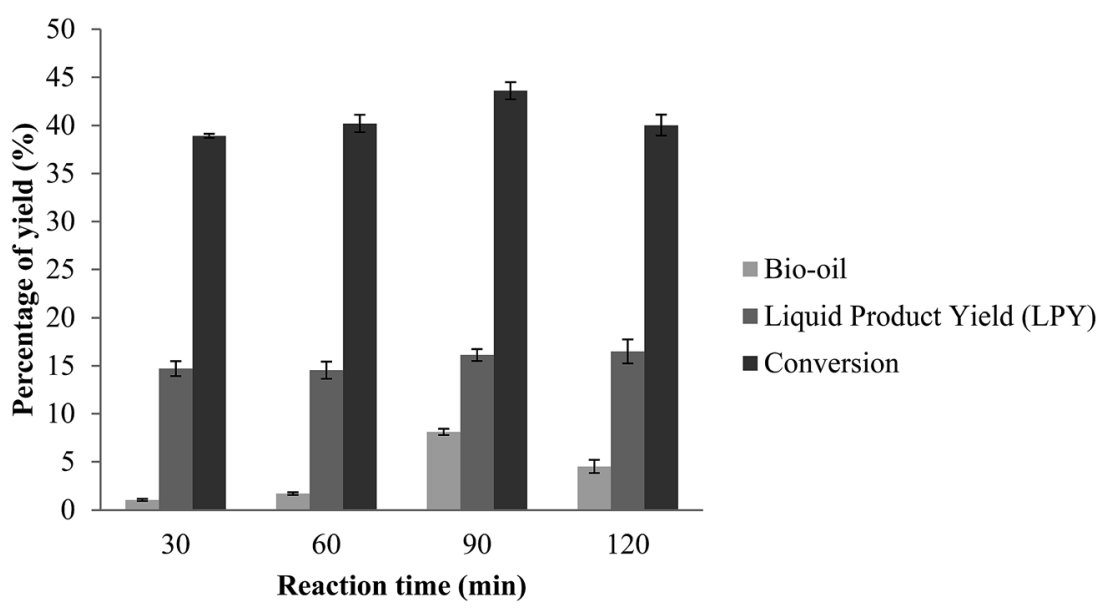

Fig. 9 Effect of reaction time on yield. Reaction condition: EFB amount of $5.0 \mathrm{~g}$, reaction temperature of $180{ }^{\circ} \mathrm{C}$, catalyst amount of $0.5 \mathrm{w} / \mathrm{w} \%$, ZnO amount of $15 \mathrm{wt} \%$ of ZSM-5. 


\section{Effect of reaction time on yield}

The effect of conversion of the bio-oil on reaction time has been studied ranging from 30 minutes up to 120 minutes. Fig. 9 showed the relationship between conversion of bio-oil and reaction time. As the reaction time increased from 30 minutes to 90 minutes, the production of bio-oil also increased. Karagöz et $a l .^{40}$ reported that increased with the increment of reaction time at low temperature $\left(150^{\circ} \mathrm{C}\right)$ favoured the liquid oil yield of sawdust. But the conversion declined when reaction time further increased to 120 minutes. Highest conversion was found at 90 minutes, with a total conversion of $43.58 \%$. Further prolongation of reaction time did not enhance or produce higher yield of bio-oil. This phenomenon was also reported by Yan et al. where insignificant increase in liquid yields for longer reaction times was observed. ${ }^{19}$ These results may be attributed to decomposition and repolymerization of bio-oil to gaseous products and char with the increase of residence time. Nevertheless, the effect of the reaction time is not significant as compared to temperature, indicating that liquefaction is a thermal controlled process. ${ }^{\mathbf{4 1}}$

\section{Effect of catalyst loading on yield}

The result of the effect of conversion of bio-oil on catalyst loading could be seen in Fig. 10. After carrying out the optimization experiments, the desirable condition for the bio-oil conversion has found to be at $180{ }^{\circ} \mathrm{C}$ for 90 minutes, with 15 wt $\%$ of zinc supported on ZSM-5, while amount of fiber was kept constant at $5.0 \mathrm{~g}$. Last but not least, the conversion of EFB to bio-oil has been subjected to be tested with different amount of catalyst loading, ranging from $0 \% \mathrm{w} / \mathrm{w}$ to $1 \% \mathrm{w} / \mathrm{w}$ of catalyst loading. As the amount of catalyst loaded increased, a steady increment in the conversion yield could also be observed, and the highest yield was found to be at $0.5 \% \mathrm{w} / \mathrm{w}$ of catalyst loading. However further amount increment did not show much significant increment in the conversion yield, but slight declination at $0.75 \% \mathrm{w} / \mathrm{w}$ to $1 \% \mathrm{w} /$ $\mathrm{w}$ of catalyst loading instead. The conversion of biomass to bio-oil may reach to its saturation point, thus further loading of catalyst did not actually favor the liquid oil yield. This phenomenon is in agreement with the study of Chan et al. ${ }^{3}$ where the effect of catalyst loading on the yield of bio-oil by increasing the amount of catalyst from $1 \mathrm{wt} \%$ to $5 \%$, and from $5 \mathrm{wt} \%$ to $12 \mathrm{wt} \%$ was studied. In their work, the yield of the bio-oil increased as the amount of catalyst loading increases from $1 \mathrm{wt} \%$ to $5 \mathrm{wt} \%$. However further catalyst loading increment ( $5 \mathrm{wt} \%$ to $12 \mathrm{wt} \%$ ) showed declination in the yield obtained. Further increase in catalyst loading could cause secondary reaction where non-condensable gases will be more favorable and thus the liquid oil yield obtained is then decreased. ${ }^{42}$ Another possible reason for the declination of bio-oil yield is due to catalyst coking that result from rapid catalyst deactivation. ${ }^{43}$ High acidity ZSM-5 has been employed and modified for the enhancement of the bio-oil production in this study. With the introduction of zinc onto the parent ZSM-5 catalyst, the number of acid sites of the catalyst increased and thus increment of yield could be seen when the amount of the catalyst added into the reaction increases. However, higher acid cites of the catalyst will lead to high affinity of coke formation which explains the decrease of biooil yield when the catalyst amount is further increased to 1 $\mathrm{wt}^{\mathrm{4}}{ }^{43}$

\section{Materials and methods}

\section{Biomass, chemicals and characterization}

Oil palm empty fruit bunch (EFB) fibres that were used in this study were obtained from the Malaysia Palm Oil Board (MPOB) at UKM, Bangi, Selangor. The fibers were used as received without any prior treatment. Biomass samples were sent to the Malaysian Agricultural Research and Development Institute, (MARDI) for the composition analysis of the fibers and the properties of the fibers are shown in Table 1. Chemicals of diethyl ether, zeolite ZSM-5, zinc sulphate heptahydrate $\left(\mathrm{ZnSO}_{4} \cdot 7 \mathrm{H}_{2} \mathrm{O}\right)$ were purchased from R\&M Chemicals, Alfa Aesar and Analar®. There is no further purification needed as all the chemicals obtained are of analytical grades.

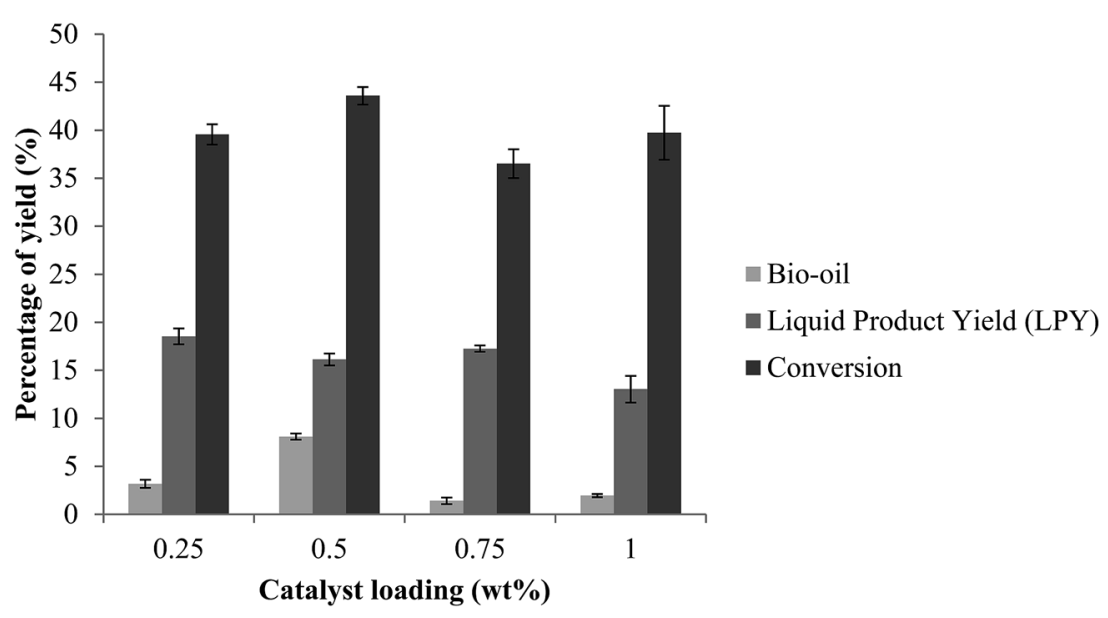

Fig. 10 Effect of catalyst loading on yield. Reaction conditions: EFB amount 5.0 g, reaction temperature of $180^{\circ} \mathrm{C}$, reaction time of 90 min, $\mathrm{ZnO}$ amount of $15 \mathrm{wt} \%$ ZSM-5. 


\section{Catalyst preparation}

Zeolite ZSM-5 was calcined at $550{ }^{\circ} \mathrm{C}$ for $6 \mathrm{~h}$ prior to the wet impregnation of zinc sulphate heptahydrate onto the zeolite as a procedure of activating the active sites of zeolite. Next, a solution of zinc sulphate heptahydrate was added to the suspension of zeolite and the mixture was stirred for $4 \mathrm{~h}$ under reflux condition. In this study, different zinc composition was added to the parent catalyst ZSM-5. The composition of zinc added includes $5 \mathrm{wt} \%, 10 \mathrm{wt} \%, 15 \mathrm{wt} \%$ and $20 \mathrm{wt} \%$ of zeolite ZSM-5. After that, the mixture was placed in oven overnight for water removal. Lastly, the dried product was calcined again at $900{ }^{\circ} \mathrm{C}$ in order to obtain zinc in oxide form.

\section{Catalyst characterization}

X-ray diffraction (XRD) analyses were carried out using Shimadzu Model XRD 6000 with its diffractometer which employs $\mathrm{Cu}-\mathrm{K}_{\alpha}$ radiation generated by Philips glass diffraction X-ray tube broad focus $2.7 \mathrm{~kW}$ to produce diffraction patterns from powder crystalline samples at ambient temperature. The catalysts were scanned at a scanning rate of $1^{\circ} \min ^{-1}$ using $2 \theta$ in the range of $2-80^{\circ}$. Strength of synthesized solid heterogeneous acid catalysts were determined by temperature programmed desorption of ammonia $\left(\mathrm{NH}_{3}\right)$. Thermo Finnigan TRD/R/O 1100 instrument coupled with a thermal conductivity detector (TCD) was employed in the catalyst strength investigation.

Brunauer-Emmer-Teller (BET) method was employed to study the total surface area of synthesized catalyst by using Thermo Finnigan Sortomatic 1990 series nitrogen adsorption/ desorption analyzer. Scanning electron microscopy equipped with energy dispersive X-ray (FEI Quanta SEM Model 400F) was employed. The composition of the synthesized catalysts was examined by EDX to examine the size of the particles and study the morphology of the catalyst.

The chemical composition of the obtained produced oil products were analyzed by using Gas Chromatography (GC) and the compound was determined by Mass Spectrometry (MS). The column used in this study was SGE BPX5 $30 \mathrm{~m} \times 0.25 \mathrm{~mm}$ I.D $\times$ $0.25 \mu \mathrm{m}$ film thickness. The velocity of carrier gas was $44.4 \mathrm{~cm}$ $\mathrm{s}^{-1}$. The heating of column started at $50{ }^{\circ} \mathrm{C}$ at heating rate of $10{ }^{\circ} \mathrm{C} \min ^{-1}$. And then raised to $300{ }^{\circ} \mathrm{C}$ and kept 10 minutes.

\section{Experimental procedure}

The solvolysis liquefaction reaction was performed by using the method as per described by Liu et al. ${ }^{6}$ All of the liquefaction reaction of EFB was carried out in an autoclave with external heating system. Briefly, the autoclave was loaded with $5.0 \mathrm{~g}$ of EFB fiber in dry basis and $50 \mathrm{ml}$ water with a specific amount of synthesized catalyst. The biomass-to-water ratio was fixed at $1: 10$ in this study. Before each run, the autoclave was purged with nitrogen gas for at least $15 \mathrm{~min}$ to displace air in the autoclave. The mixture was then heated to the desired reaction temperature $\left(180^{\circ} \mathrm{C}\right)$ with continuous stirring for a total period of 30, 60, 90 and $120 \mathrm{~min}$. After the reaction, the autoclave was allowed to cool down naturally to room temperature. The solid and liquid mixture was filtered by suction filtration and washed with solvent. The liquid product obtained was denoted as liquid product yield (LPY). Then, the liquid product was extracted with non-polar diethyl ether solvent and separated into solvent soluble and solvent insoluble parts (i.e. diethyl-ether soluble and diethyl-ether insoluble). The solvent soluble part was then recovered by evaporating the solvent and the remaining product after solvent evaporation was denoted as bio-oil. In short, LPY is equivalent to total yield of diethyl-ether soluble (bio-oil) and diethyl-ether insoluble. The yield of conversion, liquid products yield (LPY) and bio-oil is calculated by using equations as below. ${ }^{3}$

$$
\text { Conversion }(\%)=\left[1-\frac{(\text { mass of solid residue })(\mathrm{g})}{\text { mass of biomass used }(\mathrm{g})}\right] \times 100 \%
$$

$$
\begin{aligned}
\text { Liquid product yield }(\%)= & \frac{\text { mass of liquid products }(\mathrm{g})}{\text { mass of biomass used }(\mathrm{g})} \\
& \times 100 \%
\end{aligned}
$$

Bio-oil yield $(\%)=\frac{\text { mass of bio-oil obtained }(\mathrm{g})}{\text { mass of biomass used }(\mathrm{g})} \times 100 \%$

\section{Conclusions}

This study showed bio-oil could be successfully converted from oil-palm empty fruit bunch via liquefaction by using water as green solvent. In addition, the production of the bio-oil is further enhanced with the presence of catalyst. Zinc supported on zeolite ZSM-5 has shown to be active for the conversion of biomass in water. Characterizations of the catalyst have further confirmed that different zinc composition loaded on ZSM-5 was successfully synthesized. The optimum condition for the highest yield conversion was found to be at $180{ }^{\circ} \mathrm{C}$ for 90 minutes with $0.5 \mathrm{wt} \%$ catalyst loading of $15 \mathrm{wt} \%$ zinc supported on ZSM5 . It is found that the bio-oil produced under this optimum condition contains approximately $83 \%$ of furfural as its major component, followed by phenols and other minor aromatic hydrocarbons. The potential of water as green solvent to liquefy biomass into bio-oil in this study has impute another possibility of converting biomass to bio-oil by using water instead of organic solvents in liquefaction, and hence creates many future opportunities for further research and development in this area.

\section{Acknowledgements}

The author would like acknowledge University Putra Malaysia for supporting this research. A special thanks to all coworkers from PutraCat who provided insight and expertise that greatly assisted the research.

\section{References}

1 S. H. Shuit, K. T. Tan, K. T. Lee and A. H. Kamaruddin, Energy, 2009, 34, 1225-1235.

2 A. Demirbaş, Energy Convers. Manage., 2001, 42, 1357-1378. 
3 Y. H. Chan, S. Yusup, A. T. Quitain and Y. Uemura, J. Supercrit. Fluids, 2014, 95, 407-412.

4 P. Pan, C. Hu, W. Yang, Y. Li, L. Dong, L. Zhu and Y. Fan, Bioresour. Technol., 2010, 101, 4593-4599.

5 S. Yaman, Energy Convers. Manage., 2004, 45, 651-671.

6 Z. Liu and F. S. Zhang, Energy Convers. Manage., 2008, 49, 3498-3504.

7 A. V. Bridgwater, Biomass Bioenergy, 2012, 38, 68-94.

8 A. Kruse and E. Dinjus, J. Supercrit. Fluids, 2007, 39, 362-380.

9 T. Aysu and M. M. Küçük, J. Supercrit. Fluids, 2013, 83, 104123.

10 L. Lin, Y. Yao, M. Yoshioka and N. Shiraishi, Carbohydr. Polym., 2004, 57, 123-129.

11 W. P. Q. Ng, L. L. Hon, Y. N. Foo, M. Kamal and J. E. L. Heng, J. Cleaner Product., 2012, 34, 57-65.

12 Y. Ren, F. Zhang, W. Hua, Y. Yue and Z. Gao, Catal. Today, 2009, 148, 316-322.

13 X. Zhao, L. Wei, S. Cheng, Y. Huang, Y. Yu and J. Julson, Fuel Process. Technol., 2015, 139, 117-126.

14 B. S. Clausen, H. Topsøe and R. Frahm, Adv. Catal., 1998, 42, 315-344.

15 S. Fan, S. Zakaria, C. Chia, F. Jamaluddin, S. Nabihah, T. Liew and F. Pua, Bioresour. Technol., 2011, 102, 3521-3526.

16 J. Yip, M. Chen, Y. S. Szeto and S. Yan, Bioresour. Technol., 2009, 100, 6674-6678.

17 Y. Wang, H. Wang, H. Lin, Y. Zheng, J. Zhao, A. Pelletier and K. Li, Biomass Bioenergy, 2013, 59, 158-167.

18 S. Karagöz, T. Bhaskar, A. Muto, Y. Sakata, T. Oshiki and T. Kishimoto, Chem. Eng. J., 2005, 108, 127-137.

19 Y. J. Yan, J. Xu, T. C. Li and Z. W. Ren, Liquefaction of sawdust for liquid fuel, Fuel Process. Technol., 1999, 60, 135-143.

20 F. Xu, Y. Xu, R. Lu, G. P. Sheng and H. Q. Yu, J. Agric. Food Chem., 2011, 59, 9243-9249.

21 T. M. Almeida, M. D. Bispo, A. R. Cardoso, M. V. Migliorini, T. Schena, M. de Campos and E. B. Caramao, J. Agric. Food Chem., 2013, 61, 6812-6821.

22 L. Suqi, L. Caceres, K. Schieck, C. J. Booker, B. M. McGarvey, K. K. C. Yeung and I. M. Scott, J. Agric. Food Chem., 2014, 62, 3610-3618.

23 H. M. Liu, B. Feng and R. C. Sun, J. Agric. Food Chem., 2011, 59, 10524-10531.
24 P. Yu, H. Xin, Y. Ban and X. Zhang, J. Agric. Food Chem., 2014, 62, 4039-4047.

25 H. Xin and P. Yu, J. Agric. Food Chem., 2013, 61, 3926-3933. 26 W. Shi, Y. Gao, G. Yang and Y. Zhao, J. Agric. Food Chem., 2013, 61, 7574-7582.

27 T. Milne, F. Agblevor, M. Davis, S. Deutch and D. Johnson, inDevelopments in thermochemical biomass conversion, 1997, pp. 409-424.

28 Q. Lu, C. Dong, X. Zhang, H. Tian, Y. Yang and X. Zhu, J. Anal. Appl. Pyrolysis, 2011, 90, 204-212.

29 Y. Qian, C. Zuo, J. Tan and J. He, Energy, 2007, 32, 196-202.

30 J. Akhtar and N. A. S. Amin, Renewable Sustainable Energy Rev., 2011, 15, 1615-1624.

31 Y. Chen, Y. Wu, P. Zhang, D. Hua, M. Yang, C. Li, Z. Chen and J. Liu, Bioresour. Technol., 2012, 124, 190-198.

32 P. E. Savage, R. B. Levine and C. M. Huelsman, RSC Energy Environ. Ser., 2010, 192-221.

33 P. J. Valdez, M. C. Nelson, H. Y. Wang, X. N. Lin and P. E. Savage, Biomass Bioenergy, 2012, 46, 317-331.

34 O. Muraza and A. Galadima, Ind. Eng. Chem. Res., 2014, 53, 17869-17877.

35 K. Nakajima, Y. Baba, R. Noma, M. N. Kitano, J. Kondo, S. Hayashi and M. Hara, J. Am. Chem. Soc., 2011, 133, 4224-4227.

36 V. Choudhary, S. I. Sandler and D. G. Vlachos, ACS Catal., 2012, 2, 2022-2028.

37 V. Choudhary, A. B. Pinar, S. I. Sandler, D. G. Vlachos and R. F. Lobo, ACS Catal., 2011, 1, 1724-1728.

38 Y. Román-Leshkov, M. Moliner, J. A. Labinger and M. E. Davis, Angew. Chem., Int. Ed., 2010, 49, 8954-8957.

39 C. M. Lew, N. Rajabbeigi and M. Tsapatsis, Microporous Mesoporous Mater., 2012, 153, 55-58.

40 S. Karagöz, T. Bhaskar, A. Muto, Y. Sakata and M. A. Uddin, Energy Fuels, 2004, 18, 234-241.

41 F. Wang, Z. Chang, P. Duan, W. Yan, Y. Xu, L. Zhang, J. Miao and Y. Fan, Bioresour. Technol., 2013, 149, 509-515.

42 Y. H. Chan, K. V. Dang, S. Yusup, M. T. Lim, A. Mohd Zain and Y. Uemura, J. Energy Inst., 2014, 87, 227-234.

43 J. Huang, W. Long, P. K. Agrawal and C. W. Jones, J. Phys. Chem. C, 2009, 113, 16702-16710. 